\title{
STOCHASTIC MICRO-MODELLING OF HISTORIC MASONRY
}

\author{
JOHN ADAMEK ${ }^{*}$ AND PETR KABELE ${ }^{2}$
}

\author{
${ }^{1}$ Buro Happold Engineering \\ 17 Newman Street, Fitzrovia, London, United Kingdom W1T 3EQ \\ e-mail: john.adamek@burohappold.com (*corresponding author) \\ ${ }^{2}$ Faculty of Civil Engineering, Czech Technical University in Prague \\ Thákurova 7, 16629 Prague 6 - Dejvice, Czech Republic \\ e-mail: petr.kabele@fsv.cvut.cz
}

Keywords: Historic masonry structures, nonlinear finite element analysis, micro-modelling, spatial variability of material parameters, random fields

\begin{abstract}
The non-linear analysis of historic masonry structures can be difficult to perform due to the highly irregular geometric features, the inherent variability within the materials, as well as the limited amount of experimental data available. The present work details a specific methodology and result for the analysis of the compressive strength of the masonry found in walls of St. Ann's Church in the Czech Republic. A multi-scale 2D finite element modelling approach was adopted. In a mesoscale-level representation of masonry, "small stones" were grouped in with the mortar and treated as a matrix component with homogenized properties, while large stones were treated as discrete inhomogeneities. To characterize this matrix component, microscale-level models were used, in which only the "small stones" and mortar were represented. By simulating uniaxial compression and tension tests on multiple microscalelevel models, statistical distributions for compressive and tensile strength, stiffness, and fracture energy were determined. On the mesoscale-level, overall stiffness and compressive strength were determined by simulating uniaxial compression tests on models involving only the large stones embedded in the homogenized matrix. The matrix was considered either as spatially uniform or variable. In the latter case, it was modeled with random fields based on the properties' distributions obtained from the micro-scale model analyses. Furthermore, the multi-scale study was performed for two different threshold sizes defining the "small stones" to compare differences. Approximate qualitative methods were utilized to validate the results.
\end{abstract}

Overall, decreasing compressive strength was observed from the plain mortar to the microscale model of mortar with "small stones" to the meso-scale model of masonry. Models where matrix variability was represented with random fields exhibited similar failure mechanisms but with strengths 5-6\% lower than models with a uniform matrix. Therefore, the effect of the spatial variability of the matrix properties was deemed insignificant. 


\section{INTRODUCTION}

Historic masonry structures are oftentimes highly complex to analyze due to their inherent inhomogeneity on a local and global scale caused by the numerous geometric and material variabilities. While physical experiments offer a good way to estimate load and deformation capacities of masonry structures, they are very limited in scope when compared to the possible formations and variations of built masonry that exist in the world today [1]. The complex geometry and behavior of masonry is often modelled through the finite element method (FEM), where masonry can be idealized into macro-models, meso-models and micro-models [2]. Through recent advances in computer programming, masonry walls can be geometrically analyzed, and random, statistically representative geometries can be generated. Additionally, a few studies have been done reviewing the importance of the spatial variation of microparameters of masonry $[2,3]$. Based on the research done, the pairing of statistical analyses with structural analyses is shown to be beneficial when dealing with unknown materials or materials with highly variable properties, such as masonry [1]. In the present paper, a methodology is presented, which utilizes a multi-scale micro-modelling approach together with a stochastic non-linear analysis to obtain an overall compressive strength and stiffness of masonry, which can eventually be used in a structural-scale analysis of historic buildings. The procedure will be demonstrated on a case study of St. Ann's Church in the Czech Republic.

\section{STATE OF ART REVIEW}
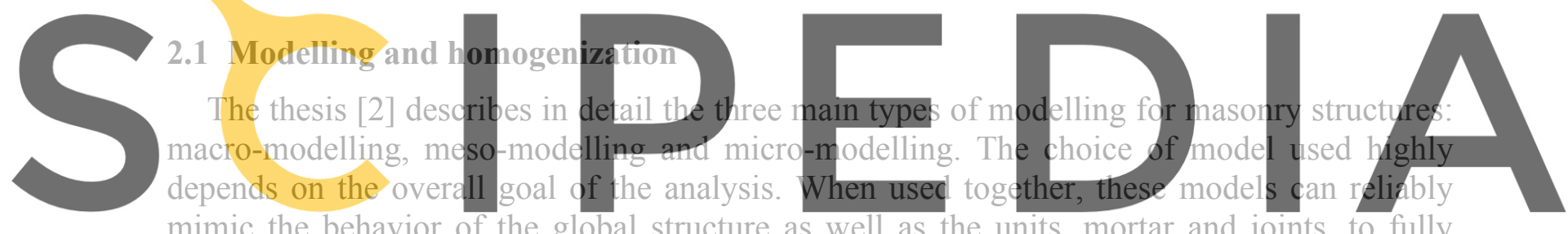

mimic the behavior of the global structure as well as the units, mortar and joints, to fully

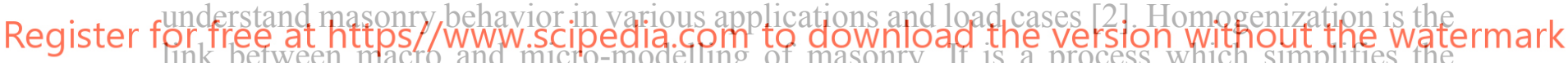

material into an equivalent continuum that represents the overall properties but disregards specific details on the units and mortar. Homogenization can be used to evaluate the linear and non-linear behavior of masonry and produces comparable results to that of experimental data [4]. Homogenization can be achieved using a representative volume element (RVE). The size of an RVE should be large enough to contain enough material inhomogeneities when viewed from the smaller-scale perspective (e.g. micro) but also small enough so that overall stress and strain variations within it are negligible when seen in the larger-scale model (e.g. macro). Then, by averaging micro-scale stress and strain fields over an RVE, one can obtain stress and strain in the corresponding material point on the macro-scale. By analyzing the behavior of the RVE under different suitable boundary conditions, the macro-scale stress-strain constitutive relations can be obtained.

Non-periodic masonry is defined as masonry containing units as well as mortar of irregular shapes and dimensions, with the spatial distribution of units and mortar being random. Since many historical structures are characterized by non-periodic masonry, studies such as $[4,5,6]$, have utilized stochastic continuum micro-mechanics in unison with RVEs to determine a homogenized equivalent continuum. In [4], the elastic stiffness tensor of an RVE of a non- 
periodic masonry structure was estimated by averaging results obtained from various arbitrarily chosen RVEs with randomized essential and natural boundary conditions. In a further study done in [6], a multitude of finite-sized test windows were made inside of a chosen RVE and an enhanced two-step convergence criterion was utilized, one being probabilistic and another mechanical, to determine if the test windows statistically match the RVE. From the analysis it was determined that a test-window size approximately 5 times the size of the largest dimension of stone was sufficient to statistically limit the geometric difference from the RVE [6].

\subsection{Stochastic characterization of irregular geometry and material properties}

When dealing with irregular geometry of units and joints, stochastic characterization of masonry can be utilized to account for the irregularities. For example, the authors of [5] applied the theory of random fields to determine the overall elastic properties of irregular masonry. Starting with the digital image processing of an image of the masonry, they evaluated the characteristics of the geometry and obtained statistical information in both the space and frequency domains. Correlation functions were then used to generate random fields to describe the geometric properties of masonry taking into account the deterministic properties of each constituent [5].

Typically, micro-models assume uniform material properties of individual phases. However, due to workmanship factors such as the batching of mortar, filling of joints, and factors effecting the curing of mortar, local material properties exhibit a spatial variation. For example, in [3], auto-correlated randoin distributions of the stre The results in [3] shor correlation length of the material properties should not be neglected as

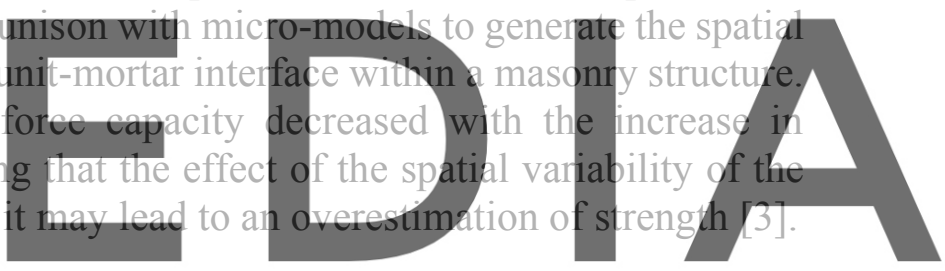

3 METHOLOGY AND APPLICATION

Register for free at https//www.scipedia.com to download the version without the watermark 3.1 History

Built in the early $18^{\text {th }}$ century, St. Ann's Church is part of the Broumov Group of Churches located in the Czech Republic. The outer wall is composed of a three-leaf masonry, consisting of locally sourced stone. The external leaves contain irregularly shaped units of highly varying sizes with 5 stone types identified as ignimbrite, yellow sandstone, red sandstone, fine grained red sandstone, and light sandstone. The wall units are bonded together with natural hydraulic lime mortar. The internal leaf is thought to be filled with rubble infill. The walls are $1.2 \mathrm{~m}$ thick, with the external and internal layers $0.5 \mathrm{~m}$ wide and the infill $0.2 \mathrm{~m}$.

\subsection{Geometric statistical analysis}

Due to the irregularity in stone size, shape, and placement, the external masonry leaf of St. Ann's Church was statistically analyzed to determine geometric detail of the models to be used for the analysis. The evaluation was completed by analyzing digital images of the front view of 6 sample wall panels with a size of $1 \mathrm{~m}^{2}$. The size was approximately 3 times larger than the projected area of the largest stone observed within the structure. Images of two of the wall panels can be seen in Figure 1. 

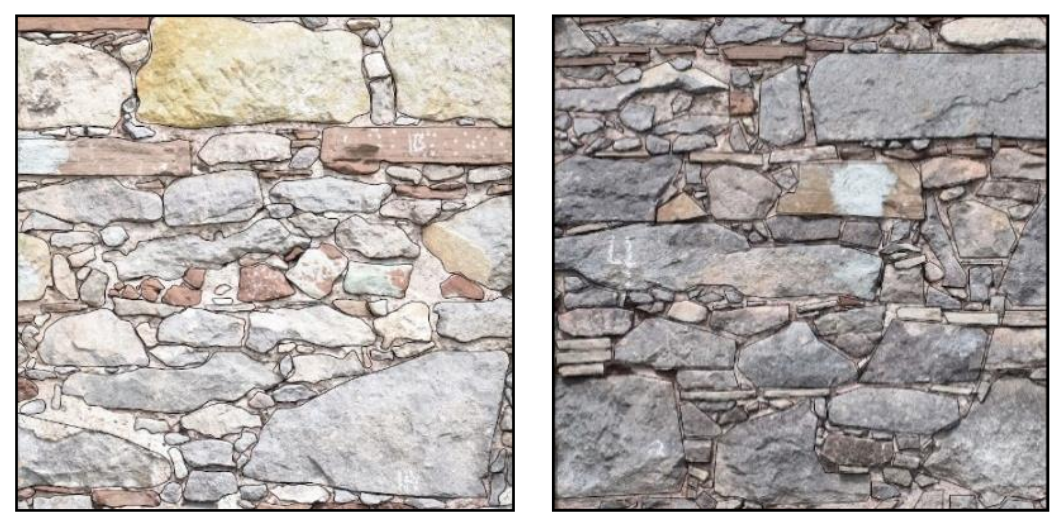

Figure 1: Wall section samples ( 2 of 6$)$

Results of the statistical analysis are illustrated in Figure 2. It was found that $80 \%$ of the area on average is stone, with the remaining $20 \%$ taken up by mortar. Utilizing a cumulative distribution function, it was seen that the size (projected area) of approximately 50\% of stone elements was less than $0.001 \mathrm{~m}^{2}$, and the size of approximately $68 \%$ of stones was less than $0.002 \mathrm{~m}^{2}$
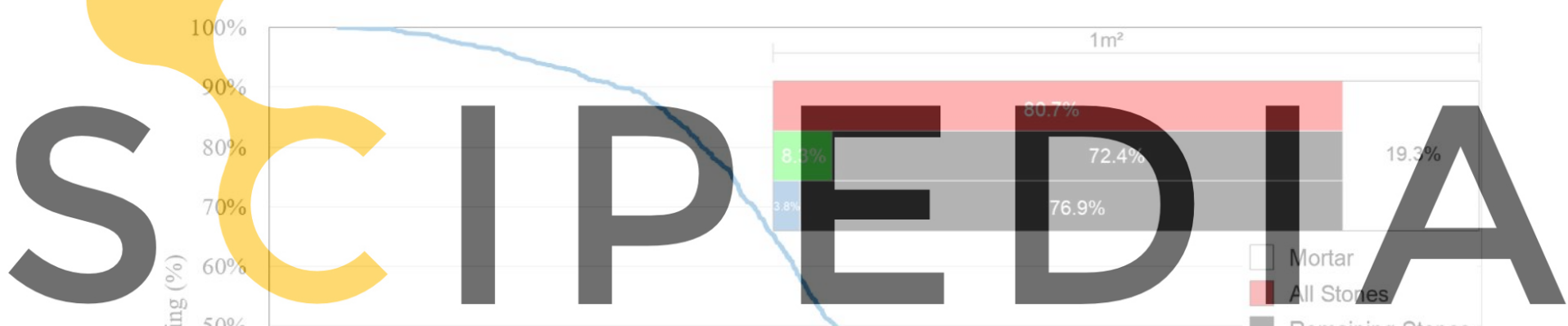

Remaining Stones

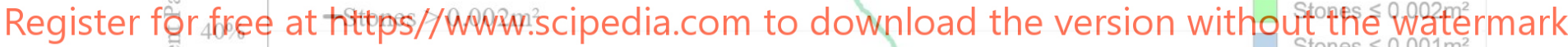

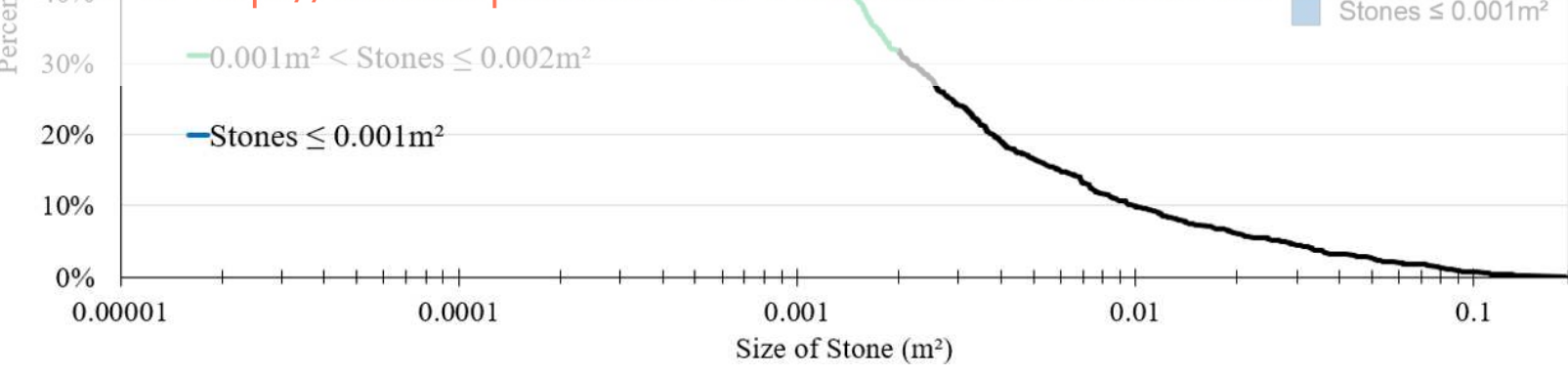

Figure 2: Statistical analysis of geometry of masonry wall sections and cumulative distribution of stone size

\subsection{Material properties of masonry constituents}

A combination of non-destructive and minor-destructive test methods were utilized to assist in the determination of material properties of the masonry constituents. More specifically, Schmidt hammer testing, masonry coring, SEM analyses, and porosity testing were completed in addition to obtaining expert estimates and reviewing past research $[8,9]$. A summarized list of values used in the analyses can be found in Table 1. 
Table 1: Summary of material properties (values based on expert estimate / research marked by ${ }^{*}$ )

\begin{tabular}{cccccccc}
\hline Material & $\begin{array}{c}\text { Unit } \\
\text { Weight } \\
\left(\mathrm{kN} / \mathrm{m}^{3}\right)\end{array}$ & $\begin{array}{c}\text { Young's } \\
\text { Modulus, } \\
\mathrm{E}(\mathrm{GPa})\end{array}$ & $\begin{array}{c}\text { Poisson's } \\
\text { Ratio }\end{array}$ & $\begin{array}{c}\text { Compressive } \\
\text { Strength, } \\
\mathrm{f}_{\mathrm{c}}(\mathrm{MPa})\end{array}$ & $\begin{array}{c}\text { Tensile } \\
\text { Strength, } \\
\mathrm{f}_{\mathrm{t}}(\mathrm{MPa})\end{array}$ & $\begin{array}{c}\text { Fracture } \\
\text { Energy, } \\
\mathrm{G}_{\mathrm{f}}(\mathrm{N} / \mathrm{m})\end{array}$ & $\begin{array}{c}\text { Ultimate } \\
\text { Compressive } \\
\text { Strain, } \varepsilon(\%)\end{array}$ \\
\hline Lime Mortar & 17.0 & $0.126^{*}$ & $0.17^{*}$ & $1.5^{*}$ & $0.10^{*}$ & $10^{*}$ & $1.2^{*}$ \\
Ignimbrite & 21 & 9.49 & 0.2 & 42 & $4.2^{*}$ & $60^{*}$ & $1.5^{*}$ \\
Yellow Sandstone & 21 & 7.51 & 0.2 & 29 & $2.9^{*}$ & $35^{*}$ & $1.5^{*}$ \\
F.G. Red Sandstone & 21 & 9.21 & 0.2 & 48 & $4.8^{*}$ & $40^{*}$ & $1.5^{*}$ \\
Light Sandstone & 21 & 8.50 & 0.2 & 45 & $4.5^{*}$ & $40^{*}$ & $1.5^{*}$ \\
Red Sandstone & 21 & 5.41 & 0.2 & 38 & $3.8^{*}$ & $40^{*}$ & $1.5^{*}$ \\
\hline
\end{tabular}

\subsection{Multi-scale modelling approach}

The goal of the ensuing analyses was to estimate overall stiffness and strength of the frontleaf of the masonry wall by numerically simulating compressive tests, while accounting for its topology (Section 3.2) and the properties of its constituents (Section 3.3). As obvious from Figures 1 and 2, the masonry is highly irregular and consists of stones whose sizes span a broad range. Constructing a compatible finite element (FE) mesh over such a complex geometry proved to be a difficult task, even when using advanced meshing algorithms. Furthermore, the resulting models consisted of a very high number of elements, thus performing non-linear calculations was not feasible. Therefore, a multi-scale modelling approach was used. To this end, three scales with

methodology (Figure 3 )

approaches reviewed in

- Macro-scale corresponds to the represented as
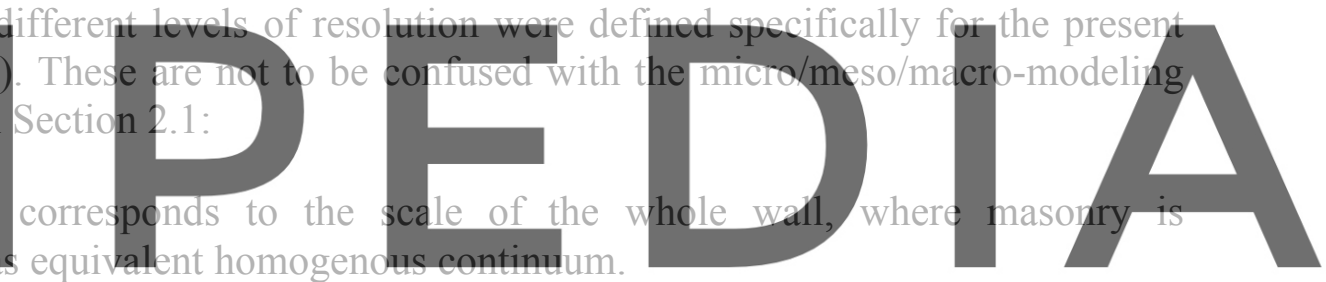

- Meso-scale corresponds to the scale of a typical wall panel, where only large stones

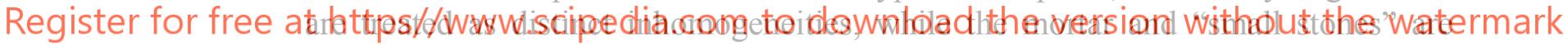
treated together as one matrix phase.

- Micro-scale corresponds to the scale of the joints between the large stones, which consists of "small stones" (as inhomogeneities) and mortar (as matrix).

The feasibility and quality of the meso-scale FE meshing in conjunction with the stones' cumulative frequency in the wall panels were both considered to decide the threshold size below which stones were classified as "small". In order to check sensitivity of the results to the definition of "small stones", analyses were conducted with two threshold size (projected area) values: $0.001 \mathrm{~m}^{2}$ and $0.002 \mathrm{~m}^{2}$. These values correspond to $50 \%$ and $68 \%$ of all the stones, respectively, as was shown in Section 3.2. Furthermore, these stone elements were thought to be small enough in size that they do not extend into the wall along the full depth of the first leaf $(0.5 \mathrm{~m})$ and, thus, could be combined with mortar in the 2D model.

The overall homogenized properties on each upper scale were obtained by numerically simulating material tests on representative square samples of the lower-scale structure. To this end, a sliding support was assigned to one edge and uniform normal displacement was applied along the opposite edge of the models (Figures 5a and 6a). Modelling and non-linear analyses were completed utilizing ATENA Science finite element software [10], assuming plane stress 
and using triangular elements. A fracture-plastic constitutive material model, called "3D Nonlinear Cementitious 2" [10], along with a fixed crack model and an exponential tractionseparation law were used both for the matrix and the inhomogeneities (stones) with parameters listed in Table 1. The unit-mortar interfaces were modelled as rigid. The Newton-Raphson method was used to complete the analyses along with an energy error convergence tolerance of $10^{-4}$.

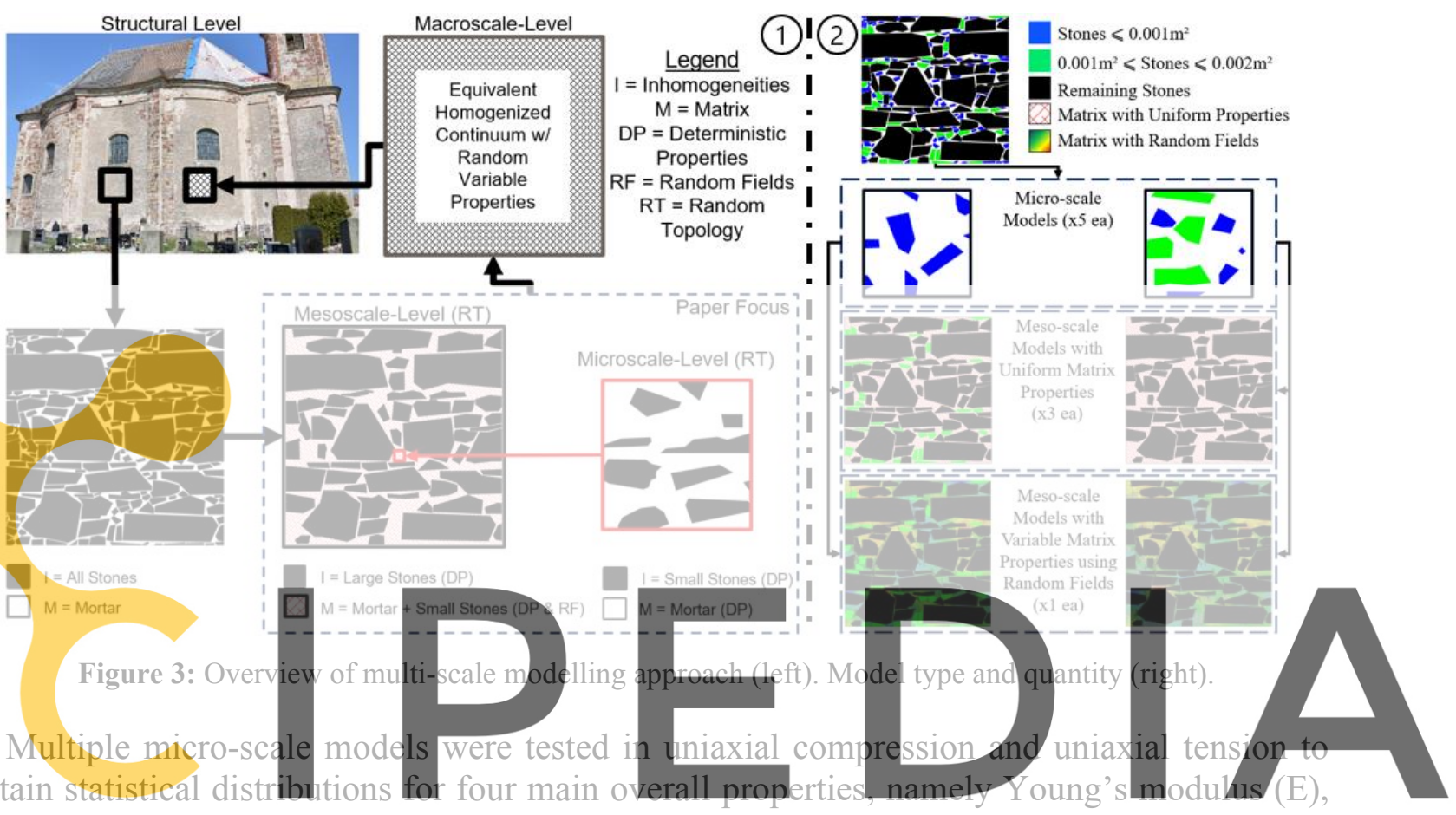

compressive strength $\left(\mathrm{f}_{\mathrm{c}}\right)$, tensile strength $\left(\mathrm{f}_{\mathrm{t}}\right)$, and fracture energy $\left(\mathrm{G}_{\mathrm{f}}\right)$. For meso-scale models,

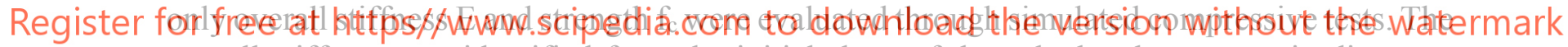
overall stiffness was identified from the initial slope of the calculated stress-strain diagrams (Figure 7). Stresses were determined from the reaction forces divided by the cross-sectional area and strains were determined from the applied displacements divided by the length of the specimen. The strengths were determined as the peak attained stresses. The fracture energy was calculated from the area under the softening part of the stress-displacement curves.

The original morphology (Figure 1) did not contain any portion with only "small stones" and mortar that was suitably shaped and sized to allow for a sufficiently large square sample for the micro-scale level virtual testing. Therefore, several separate FE models were built on the micro-scale level using test-windows placed in randomly generated, statistically equivalent morphologies, in which only the "small stones" and mortar were represented. These equivalent morphologies were built by extracting the "small stones" from digitalized images of the sample wall panels and putting them into equivalent area of mortar, thereby ensuring the true area fraction, size and aspect ratio of the stone elements were statistically met. From there, the "small stones" were randomly scattered within the domain utilizing the "SCATTER" function in AutoCAD. Any overlapping stones were manually moved. Test windows were randomly placed using the same function. The windows' size was set to be at least 3 times the size of the largest stone dimension found within the mortar. Since the stones were randomly placed, the smaller 
test-windows encompass the spatial variation in overall properties. The complete statistically equivalent morphologies and test windows for the two "small-stone" thresholds can be seen in Figure 4.
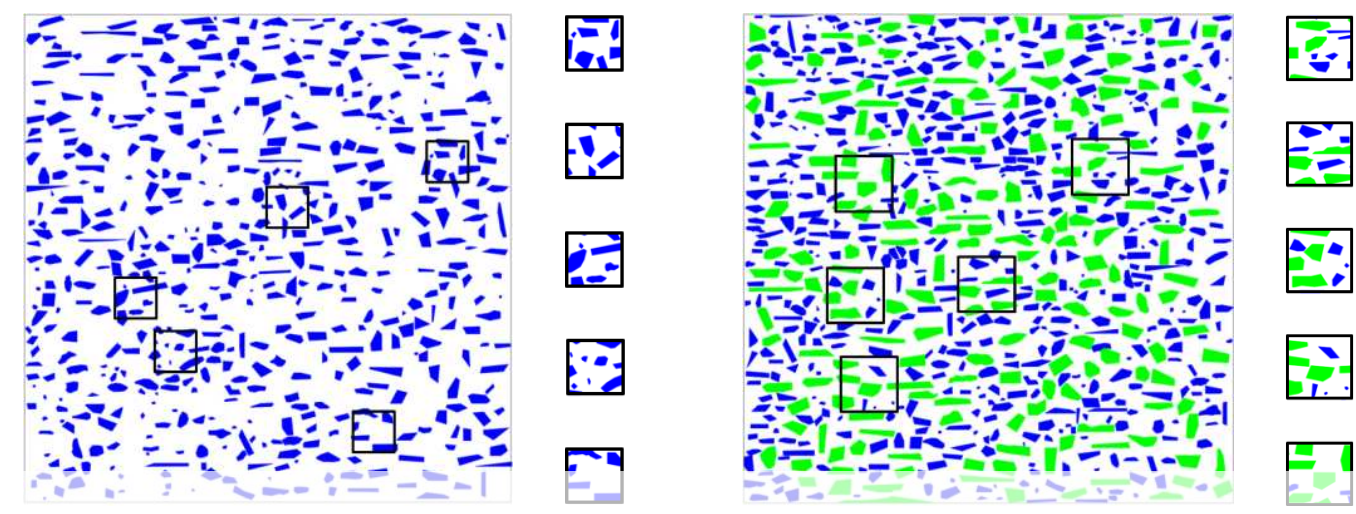

Figure 4: Statistically equivalent morphology and test-windows. Mortar with stones $\leq 0.001 \mathrm{~m}^{2}$ (left), mortar with stones $\leq 0.002 \mathrm{~m}^{2}$ (right)

The meso-scale models were constructed directly by FE discretization of the vectorized images of the sample wall panels, in which only the large stones were represented. For the meso-scale models, two sets of calculations were done. First, the matrix component was assigned uniform properties using the mean values obtained from the micro-se Second, to capture the obtained from the micr software package [11] were utilized to define the meso-scale models. were generated using the Latin hypercube sanaling method of the variables. The parameters of the distributions were defined by taking the mean and

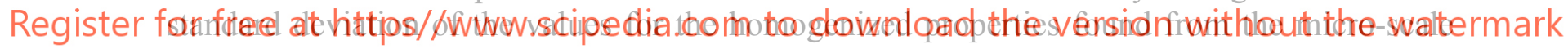
modelling analysis. The autocorrelation length, which defines the level of variability of the properties in space, was set to match the test window size of the micro-scale models studied. In total, 5 random fields were generated for the matrices of both types of meso-scale model. Due to time constraints only one meso-scale model was analyzed with random fields.

\section{RESULTS}

\subsection{Micro-scale models}

Figures 5 and 6 show the stress-strain diagrams and an example of the damage phenomena for the simulated uniaxial compression and tension tests on the micro-scale models. To interpret the failure mode under compression, contour plots for equivalent plastic strain (Figure 5b) and crack width (Figure 5c) before and after the peak stress were compared. In the fracture-plastic model, the plastic strain represents inelastic deformation due to compression. If there was a major jump in crack width without any increase in equivalent plastic strain, then the failure was categorized as tensile splitting. If the limit value of equivalent plastic strain was reached, then 
compressive failure occurred due to crushing. The deformed shape (Figure 5d) was also analyzed to help determine if tensile splitting played a major role in failure. For simulated tensile tests, the micro-scale models were analyzed using contour plots for crack width (Figure $6 b)$.

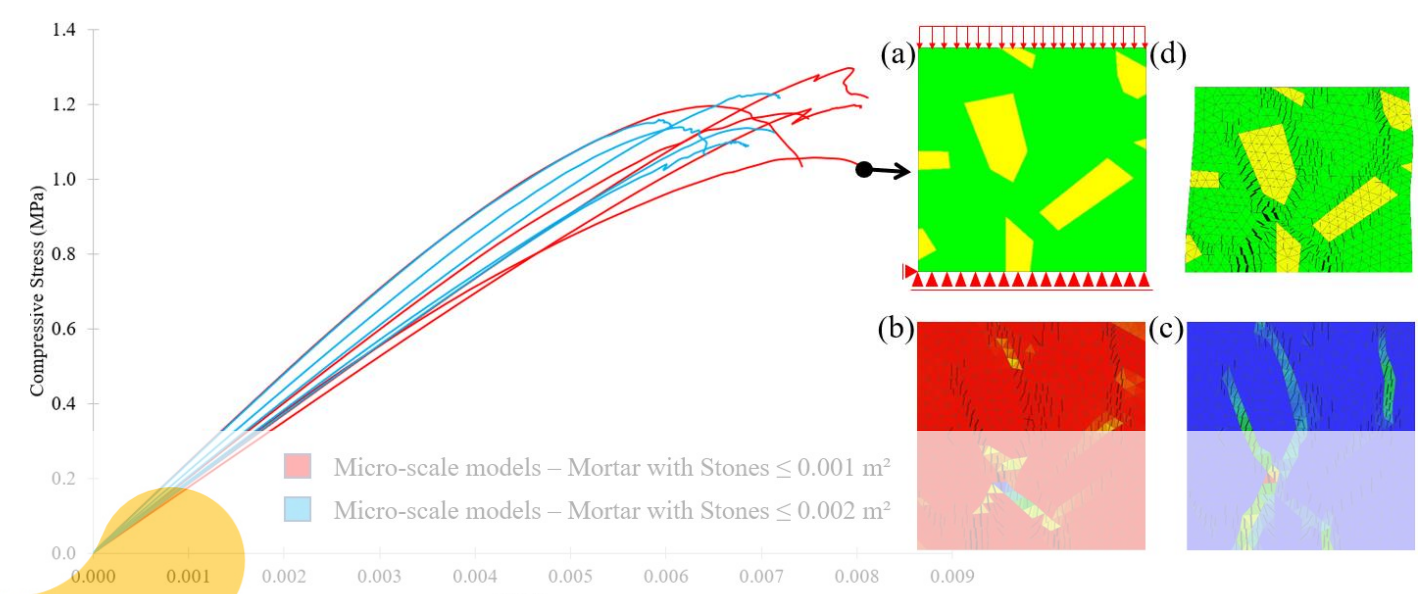

Figure 5: Stress-strain diagrams for micro-scale models under uniaxial compression test. (a) Microscale model with applied displacement and boundary conditions. (b) Post-peak equivalent plastic strain, (c) crack width, and (d) deformed shape with cracks after uniaxial compression test.
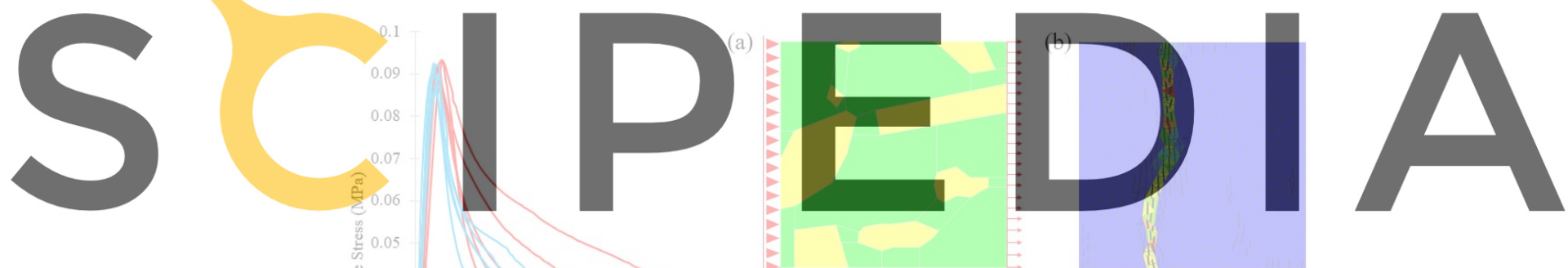

Register for free at ht:tes//www.scipedia.com to download the version without the watermark

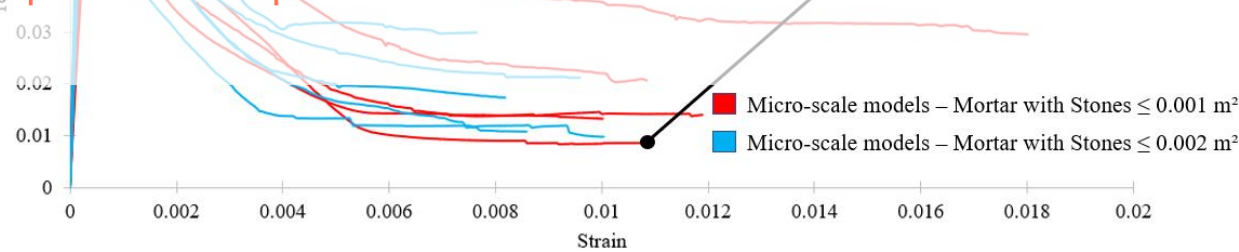

Figure 6: Stress-strain diagrams for micro-scale models under uniaxial tension test. (a) Micro-scale model with applied displacement and boundary conditions. (b) Post-peak crack width after uniaxial tension test.

The formation of cracks initiated the non-linear behaviour of the specimen. For the compressive tests, failure occurred due to compressive crushing, tensile splitting or a combination of both, depending on the sample morphology. Since the models were unrestricted along the vertical sides, they contracted in the vertical direction and expanded in the horizontal direction, which led to the formation of either one or multiple tensile splitting cracks in the mortar. Some of these cracks propagated through the entire height of the specimen leading to splitting failure, while others were constrained by the stones. High plastic strains typically developed in the mortar in the vicinity of the stiffer stones. When these regions spread over 
much of the cross section, the compressive crushing failure occurred. For the tensile tests, failure was always caused by a fully formed crack within the mortar which developed along the easiest path around the stones, thus producing a tensile strength of the specimen close to that of the mortar. High fracture energies correlated to extremely tortuous cracks. Table 2 summarizes the homogenized properties determined from the completed analyses for both stone size thresholds.

Table 2: Summary of homogenized values for all micro-scale models

\begin{tabular}{cccccc}
\hline $\begin{array}{c}\text { Type of Micro- } \\
\text { scale Model }\end{array}$ & Results & $\begin{array}{c}\text { Compressive } \\
\text { Strength, } \mathrm{f}_{\mathrm{c}}(\mathrm{MPa})\end{array}$ & $\begin{array}{c}\text { Tensile Strength, } \\
\mathrm{f}_{\mathrm{t}}(\mathrm{MPa})\end{array}$ & $\begin{array}{c}\text { Young's Modulus, } \\
\mathrm{E}(\mathrm{MPa})\end{array}$ & $\begin{array}{c}\text { Fracture Energy, } \\
\mathrm{G}_{\mathrm{f}}(\mathrm{N} / \mathrm{m})\end{array}$ \\
\hline Mortar with & Mean & 1.18 & 0.091 & 199.06 & 23.90 \\
Stones $\leq 0.001$ & St.Dev & 0.08 & 0.002 & 23.41 & 5.07 \\
$\mathrm{~m}^{2}$ & COV $(\%)$ & $6.44 \%$ & $2.05 \%$ & $11.76 \%$ & $21.22 \%$ \\
Mortar with & Mean & 1.15 & 0.090 & 208.53 & 24.82 \\
Stones $\leq 0.002$ & St.Dev & 0.04 & 0.002 & 19.79 & 2.80 \\
$\mathrm{~m}^{2}$ & COV $(\%)$ & $3.61 \%$ & $2.54 \%$ & $9.49 \%$ & $11.26 \%$ \\
\hline
\end{tabular}

The overall mean values for compressive and tensile strength of the microstructures are lower than those of the plain mortar, with little variability due to different morphologies, proving the models are heavily dependent on the properties initially set for mortar, since that is where the failure is concentrated. Furthermore, the irregular topology is shown to create stress concentrations which reduce the overall compressive strength. The modulus of elasticity and

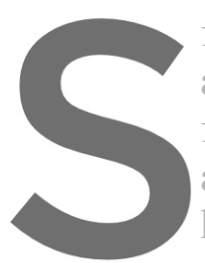
fracture energy both sh attributed to the additi fracture energy increase around the "small ston homogenized properties for the micro-scale mode differences are very minor.
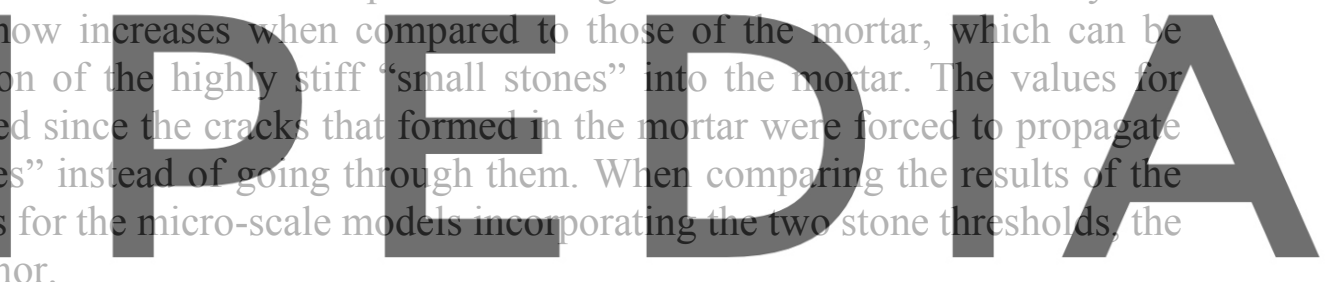

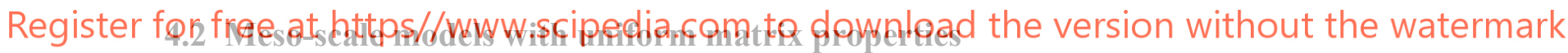

Figure 7 depicts the stress-strain results of the meso-scale models with uniform matrix properties. The failure mode was analyzed by observing contour plots for equivalent plastic strain (Figure 7b) and crack widths (Figure 7c) before and after peak stress was attained as well as the deformed shape (Figure $7 \mathrm{~d}$ ). The locations of cracks and crack width values were seen to be relatively similar between the same type of meso-model, but there was a slight increase in the number of cracks in the models with a matrix including stones less than $0.001 \mathrm{~m}^{2}$. Comparing post-peak equivalent plastic strain, the areas of concentration slightly change, with the models with a matrix including stones less than $0.002 \mathrm{~m}^{2}$ having a few additional areas. Based on the deformed shaped, it was observed that the models failed due to a combination of local compressive crushing and tensile splitting within the matrix. In summary, the higher the proportion of the stones modelled as distinct inhomogeneities and not encompassed within the matrix component (i.e. the lower is the "small-stone" threshold value), the more cracks formed due to the increased irregularity in the model topology. Furthermore, a different "small stone" threshold also led to a change in the distribution of equivalent plastic strain. These results were typical for all meso-scale models tested. Table 3 summarizes the compressive strength and stiffness data gained from each of the meso-scale models. 


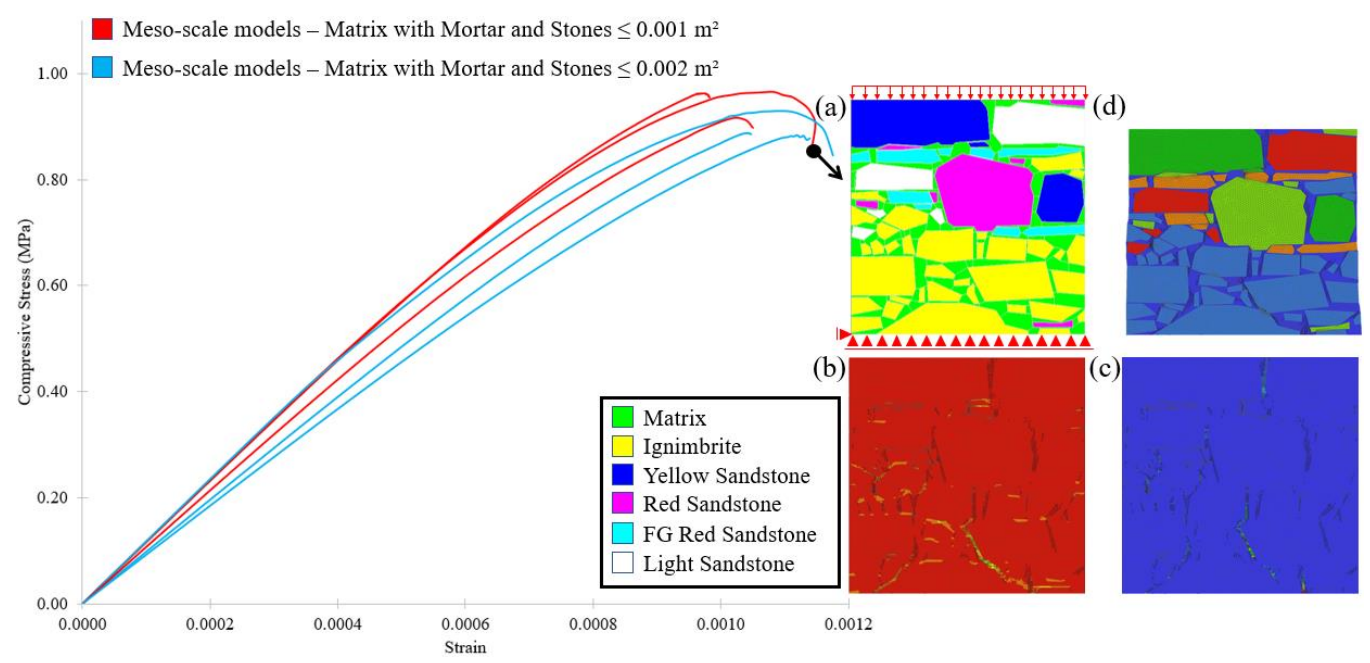

Figure 7: Stress-strain diagrams for meso-scale models with uniform matrix properties under uniaxial compression test. (a) Meso-scale model with applied displacement and boundary conditions. (b) Post-peak equivalent plastic strain, (c) crack width and (d) deformed shape after uniaxial compression test.

Table 3: Compressive strength and Young's modulus for meso-scale models with uniform matrix properties Meso-scale Models Wall Panel $1 \quad$ Wall Panel 2 Wall Panel 3 Average $\quad$ St. Dev COV (\%) Compressive Strength, $\mathrm{f}_{\mathrm{c}}(\mathrm{MPa})$
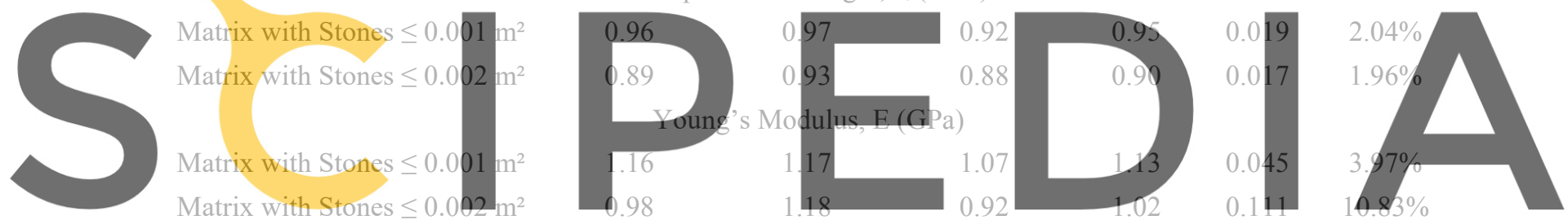

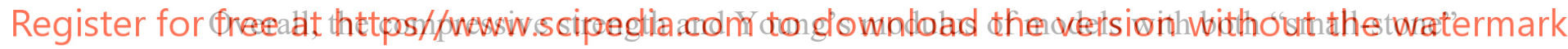

threshold values were relatively close in value with a small variance. By observing the failure mechanism for each meso-scale model, it can be concluded that the irregularity in the topology of the wall panels created stress concentrations in the weakest component, in this case being the matrix, where it failed due to combined local crushing and tensile splitting.

\subsection{Meso-scale models utilizing random fields}

Utilizing the homogenized property distributions obtained from the micro-scale model analyses, random fields were generated for the four variables $\left(f_{c}, f_{t}, E, G_{f}\right)$ of the matrix phase for meso-scale models of wall panel 2 considering both of the "small-stone" thresholds. Cracks occurred in the same locations for both models regardless of the spatial variability of the matrix material parameters. This was attributed to the low variability of the matrix strengths $f_{c}$ and $f_{t}$ (see COV in Table 2) for each random field realization. Furthermore, by comparing contour plots for the equivalent plastic strain for models with random fields versus models with a uniform matrix, it is seen that the areas of local crushing are similar. Any additional areas of local crushing are due to low compressive strengths produced by the random field for the matrix component in that area. A sample of the generated distributions for compressive strengths for 
the two types of models along with post-peak crack locations are illustrated in Figure 8. Compressive strengths from the random field analyses are summarized in Table 4.
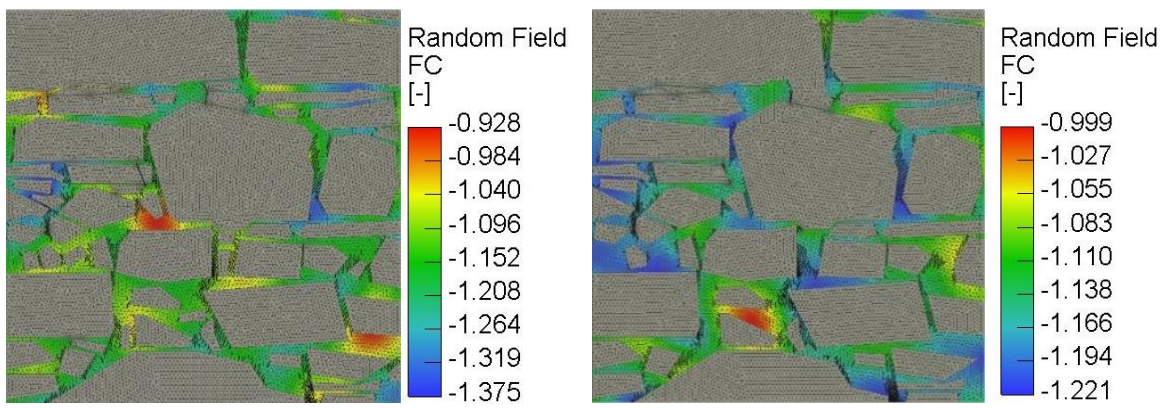

Figure 8: Random fields for $\mathrm{fc}$ and post-peak crack locations. Meso-scale model with distinct stones $>0.001 \mathrm{~m}^{2}$ (left), meso-scale model with distinct stones $>0.002 \mathrm{~m}^{2}$ (right)

Table 4: Summary of compressive strength (MPa) for wall panel 2

\begin{tabular}{lcc}
\hline \multicolumn{1}{c}{ Model } & Matrix Incl. Stones $\leq 0.001 \mathrm{~m}^{2}$ & Matrix Incl. Stones $\leq 0.002 \mathrm{~m}^{2}$ \\
\hline Model with Uniform Matrix & 0.97 & 0.93 \\
Model with Random Fields (Avg of 5) & 0.91 & 0.88 \\
\hline Mean & 0.92 & 0.89 \\
St. Dev & 0.03 & 0.02 \\
COV (\%) & $3.50 \%$ & $1.98 \%$ \\
\hline
\end{tabular}

Based on the results, by considering spatial variability of the matrix, the overall compressive strength of the masonry wall panel was reduced by $0.05 \mathrm{MPa}$ for both matrices containing different thresholds of stone sizes. The spatial variability caused a minor reduction in overall strength when compared to models with a uniform matrix, which is attributed to introduction of weaker properties on a local scale generated by the random fields.

\subsection{Verification}

To verify sanity of the results, simple comparisons for the overall uniaxial compressive strength were made to literature and other methods for historic masonry structures. First, the Masonry Quality Index (MQI) method as seen in [12], was used to determine the compressive strength based on a qualitative assessment of the walls of St. Ann's Church. Utilizing this method, an MQI of 1.05 was obtained, which correlates with a uniaxial compressive strength of around 1 $\mathrm{MPa}$. Furthermore, reviewing the Italian code for masonry, the uniaxial compressive strength of irregular stone masonry is $1-1.8 \mathrm{MPa}$ [13]. These values are comparable to the values attained from the analyses. Furthermore, the Young's modulus of $1 \mathrm{GPa}$ attained from the meso-scale models lines up with the upper limit given in [13]. The minor difference in strength could be due to the low values that were set for the mortar during the micro-scale modelling analyses.

\section{CONCLUSIONS}

Based on the multi-scale modelling approach utilized, the uniaxial compressive strength of the front leaf of the masonry walls of St. Ann's Church was determined to be $0.9 \mathrm{MPa}$. The predicted strength decreased when moving through the respective modelling levels from micro to macro. This decrease was attributed to the non-uniformity of the topology which caused 
stress concentrations in the weak material at each level, leading to combined failure mechanisms from both local compressive crushing and tensile splitting. The use of random fields showed minor decreases in compressive strength, with the location of cracks and failure mechanisms remaining similar throughout all meso-scale models. In summary, the results of this study show that the spatial variability of the matrix component can be neglected due to the small variation in the distributions of the homogenized properties obtained but should be reconsidered if the variation become larger after analyzing more randomized micro-scale models. Furthermore, the present modelling approach is shown to produce sound results and allows for the analysis of masonry in full detail by incorporating the effect of the "small stones" without having to explicitly model them on a meso-scale level. Nevertheless, a large number of micro-scale models are required to increase reliability of the statistical distribution, which leads to a time-consuming process and is therefore not recommended for use in a practical setting.

Acknowledgements. This study was completed during the SAHC MSc. program. The authors would like to thank the SAHC Consortium, David Biggs, Prof. Ing. Pavel Kuklík CSc., Ing. Zuzana Slížková Ph.D., and Červenka Consulting for their expertise and guidance.

\section{REFERENCES}

[1] Zhang, S., Hofmann, M., \& Beyer, K. (2018). A 2D typology generator for historical masonry elements. Construction and Building Materials, 184, 440-453.

[2] Lorenço, P. (1996). Computational Strategies for Masonry Structures. Delft University.

[3] Zhang, S., Taheri Mousavi, S. M., Richart, N., Molinari, J. F., \& Beyer, K. (2017). Micromechanical finite element modeling of diagonal compression test for historical stone masonry structure. International Journal of Solids and Structures, 112, 122-132.

[4] Cluni, F., \& Gusella, V. (2004). Homogenization of non-periodic masonry structures. International Journal of Solids and Structures, 41(7), 1911-1923.

[5] Falsone, G., \& Lombardo, M. (2007). Stochastic representation of the mechanical properties of irregular masonry structures. International Journal of Solids and Structures, 44(25-26), 8600-8612.

[6] Gusella, V., \& Federico, C. (2006). Random Field \& Homogenization For Masonry With Nonperiodic Microstructure. Mechanics of Materials and Structures, 1(2), 357-386.

[7] Ostoja-Starzewski, M. (2006). Material spatial randomness: From statistical to representative volume element. Probabilistic Engineering Mechanics, 21(2), 112-132.

[8] Drdácký, M., \& Slížková, Z. (2008). Mechanical Characteristics of Historical Mortars from Tests on Small-Sample Non-Standard Specimens, (January).

[9] Válek, J., \& Veiga, R. (2005). Characterisation of mechanical properties of historic mortars: testing of irregular samples. Transactions on the Built Environment, 83, 365374. Retrieved from http://cat.inist.fr/?aModele=afficheN\&cpsidt=17545867

[10] Červenka, V., Jendele, L., \& Červenka, J. (2018). ATENA Program Documentation Part 1 Theory. Črvenka Consulting. Prague.

[11] Havlasek, Petr, \& Pukl, Radomir. (2015). RLACS Studio Structural Analysis and Reliability Assessment. Červenka Consulting. Prague.

[12] Borri, A., Corradi, M., Castori, G., \& De Maria, A. (2015). Analysis and classification of historic masonry. Bulletin of Earthquake Engineering, 13(9), 2647-2665.

[13] NTC. (2008). Italian Ministry of Infrastructure and Transportation. 